\title{
Ramadan Fasting and Competitive Sports: Psychological Adaptation within Socio-cultural Context
}

\author{
Jolly Roy $^{1}$, Rabindarjeet Singh ${ }^{2}$, Anaurene Roy ${ }^{3} \&$ Shazarina Hamidan ${ }^{1}$ \\ ${ }^{1}$ Sport Psychology Centre, National Sport Institute of Malaysia, Bukit Jalil, Malaysia \\ ${ }^{2}$ Advanced Medical and Dental Institute, Universiti Sains Malaysia, Penang, Malaysia \\ ${ }^{3}$ Sports Centre, University of Malaya, Kuala Lumpur, Malaysia \\ Correspondence: Jolly Roy, Sport Psychology Centre, National Sports Institute of Malaysia, Bukit Jalil, \\ KualaLumpur, 57000, Malaysia. E-mail: jollyroyisn@hotmail.com
}

Received: August 3, 2012

Accepted: September 24, 2012 Online Published: November 12, 2012

doi:10.5539/ijps.v4n4p55

URL: http://dx.doi.org/10.5539/ijps.v4n4p55

Preparation of this article was facilitated through grants from Universiti Sains Malayasia (USM) (304/CIPPT/6310083).

\begin{abstract}
The article examines the influence of socio-cultural practices of Ramadan fasting in competitive sports and adaptation pathway of the athletes. The study describes how the socio-cultural context acts as the social "panopticon" and explains the adaptation pathways among Muslim archers. Foucauldian concept explains individual actions and behaviors within social and cultural settings, and adaptation pathways during Ramadan fasting. Eleven elite Malaysian Muslim archers participated in an open ended interview to identify individual experiences of competing in high level sports while engaging in Ramadan fasting. Relevant quotes were extracted to identify means and methods leading to a pathway toward adaptation. The inductively identified pathway viz. understanding of the context, control and adjustment, willpower and self enhancement, belonging and gravitating, trust and support culminates in the dimension of adaptation. The study highlights how cultural and societal influences have a bearing on actions, behaviors, and decisions of competitive athletes.
\end{abstract}

Keywords: adaptation, will power, self-control, fasting practices

\section{Introduction}

Culture represents the root of an individual development. It refers to the shared values, beliefs and practices of a particular group of individuals (Mio et al., 2006). Socio-cultural values, beliefs and practices are passed on from one generation to the next by virtue of socialization through social agents like family, educational institutions etc (Liem et al., 2012). Thus, in due course an individual learns to gravitate toward the practices within which he/she is raised (Brown, 2000). Athletes are no exception to this. Today, Sports science, particularly social psychology and cultural psychology has begun to contribute towards the understanding of an athlete's concerns and adaptations. The key challenge is to understand how socio-cultural practices are linked to competitive sports while staying rooted within one's belief systems. In this article we describe how Ramadan fasting impacts Muslim athletes participating at high level competitions and provide extracts from the interview data on the adaptive pathways.

\subsection{Ramadan Fasting}

During the Islamic month of Ramadan, the Muslims all over the world engage in observing fast, everyday, from dawn to dusk, which lasts for a period of 30 days and its length changes along the solar year. There are no restrictions to the type or amount of food that can be consumed during the permissible period. Normally, sahur, the first meal of the day, is taken just before commencement of the day's fast and iftar, the second meal at the breaking of the day's fast. Although, in sports settings some modifications in training timings, volume and intensity are made during the fasting month, Muslim athletes seldom cease training and competing during Ramadan. Ramadan fasting tends to disrupt the normal routine resulting in physiological and/or psychological consequences for athletes. For example, studies have reported prevalence of irritability, increased headaches, 
sleep disturbances, general fatigue, and impairment of cognitive functions (Kadri et al., 2000; Leiper et al., 2003; Tian et al., 2012). Research related to Ramadan and performance in Malaysia have been helpful in understanding how Ramadan fasting affects sports performance (see Aziz \& Weileen, 2008; Roy et al., 2011a; Roy et al., 2011b; Singh et al., 2011). Despite the existence of such research, there is a deficit of literature that examines the distinction and essential socio-cultural influences in sport setting during Ramadan. Modern day sporting events require athletes to build tangible skills to adapt effectively in highly complex and dynamic environment. While scheduling the major competitions, international sporting bodies does not take into consideration the situations of any religious/socio-cultural practices (e.g., London Olympics, 2012 falls during the Ramadan fasting month).

\subsection{Social Panopticon and Adaptations}

Socio-cultural influences are so pervasive that one cannot escape the social "panopticon" (Foucault, 1977). More specifically, moving beyond one's socio-cultural beliefs and context is not an easy task for any individual or an athlete who wish to abide by socio-cultural norms. Thus, it is important to understand the socio-cultural contextual demands and common adaptation strategies adopted by the Muslim athletes while participating in major sports events during Ramadan fasting.

Adaptation reflects the capacity to act and react functionally in one's environment, which can be achieved through deliberate actions on the part of those about to or in the midst of performance (Fiske, 2004). Every athlete strives to achieve an optimal balance through coordinated effort of his/her thoughts, emotions, and behaviors. In recent years, research has focused on adaptation pathways in elite athletes which is reflected in the works of Tenenbaum et al. (2003), Schinke et al. (2010), Schinke et al. (2006) and Tenenbaum et al. (2003) reported that elite cyclists effective adaptation to daily challenges consisted of maintaining low levels of anxiety, vigor, focus and hope, flexibility within the sport context, and positive experiences of social support. Schinke et al. (2010) proposed adaptation as a comprehensive intervention strategy for elite athletes where he emphasized the importance of providing additional psychological guidance and practical knowledge on how to transfer the learning from a sterile environment to a real world context. Roy et al. (2011a) studied the temporal patterns of subjective experiences and self-regulation during Ramadan fasting among Malaysian elite archers. This study reported an increase in experiences related to mental factors in the latter phase of Ramadan fasting. In a somewhat related study on the subjective perception of sports performance, training, sleep and dietary patterns of Malaysian junior Muslim athletes during Ramadan fasting, Singh et al. (2011) reported diverse perceptions among the athletes, leading to believe that athletes might be adopting different adaptive pathways. Roy et al. (2011b) in their study on self-generated coping strategies during Ramadan fasting among Malaysian Muslim athletes, reported that athletes employed diverse and dynamic coping strategies, with no evident pattern.

At present, little is known about athletes' adaptive pathways during Ramadan fasting and how they transfer the learning or the knowledge (Foucault, 1977) inculcated from childhood to adulthood, without compromising ones cultural practices. In a real-world sporting environment, most Muslim athletes who engage in fasting face big challenges. For instance, Muslim athletes participating in London Olympics 2012, would have equipped themselves with additional adaptive strategies to sustain in the competition, while engaging in Ramadan fasting. Alternatively, the athlete would have compromised on the fasting practices, probably resulting in psychological conflict within oneself. In both situations, the challenges are huge. Firstly, to equip with additional adaptive strategies, one should have prepared well in advance. Secondly, compromises made on one's beliefs and practices, inculcated over the years, would require athletes to muster additional psychological resources to avoid personal conflict that might adversely influence the performance competition.

While in the past, research in psychology related to Ramadan fasting and competition, addresses issues of coping strategies and self-regulation few studies focused on adaptive pathways. Although, the meaning behind the terms coping, self-regulation and adaptation are interrelated, Schinke et al. (2010) referred adaptation as more comprehensive and contextually informed pathway for elite athletes to achieve peak performance.

Research investigating elite athletes' experiences on adaptations in crucial competition under fasting conditions has to date, been sparse and lacking in detailed investigation. Hence, the present research attempts to understand how Muslim athletes abide by cultural practices and describes the adaptive pathway (Fiske, 2004) of the athletes, by eliciting meaning units from a larger pool of transcribed data.

\subsection{Theoretical Framework}

Foucauldian concepts have been used widely by sociologist and cultural psychologist in understanding human actions and behaviors within social and cultural settings (Cole et al., 2004; Markula \& Pringle, 2006). According to Foucault, there are "power mechanisms"- a disciplinary control that frames around individual's lives, which makes every individual to behave in a certain way (Foucault, 1977). With a clear understanding on this aspect, 
Foucault used the prisoners as an analogy to explain the power dynamics. Using the concept of Jeremy Bentham's "Panopticon", he explained that the body of an individual is "docile", i.e., it may be subjected, used, transformed and improved through effective means of power (Foucault, 1977). Bentham's model prison was based on an architectural figure which consisted of a guard tower at the centre of the prison cells. In this guard tower, the supervisors constantly monitored the prisoners in each cell. This made the inmates believe that they were under constant surveillance, thus, making them responsible for their own actions (Cole et al., 2004; Foucault, 1977; Markula \& Pringle, 2006). Extending the reference from the prisoners, Foucault stated that the power dynamics is not exclusive to the prisoners but its effects can be found in everyday situations as well (Foucault, 1977). Our society and our culture is a machine for learning (knowledge), in which every person at every age and at every moment, permanently utilizes the general process of teachings from different social agents (Foucault, 1977). Therefore, each of our actions, behaviors, decisions may be in relation to the cultural and societal requirements which are disciplined through surveillance from the "micro-physics" of power (Foucault, 1977) such as the different social agents around us.

Although research examining fasting practices have enhanced our understanding, limited studies have highlighted socio-cultural issues associated with Ramadan fasting and participation in competition. Thus, one of the purposes of the research was to make meaningful contribution to the literature to further capture a wide range of common findings. Socio-cultural practices can have varied consequences, respectively, for competitive athletes' psychological well-being, and therefore merit investigation.

\section{Method}

\subsection{Participants}

The participants were recruited from the elite Squad of Archery. Only those athletes who were engaged in fasting practice were considered for the study. Eleven Muslim archers (mean age $=20.1 \mathrm{y}, \mathrm{SD}=2.8$ ) volunteered to provide their subjective experiences during Ramadan fasting. All athletes had participated at national and international competitions and were attending a training camp with five to six hours of practice during this study.

Approval and ethical permission for the study were granted by the Institutional Research Committee. All participants signed an informed written consent.

\subsection{Interview Procedure}

The framework of interview was developed based on literature related to emotional experiences and subjective feelings derived from Hanin's (2000) individualized approach to emotion. Each athlete was instructed to relate their experiences during the Ramadan fasting and further relate it to the sports training. More specifically, the interview began with a general open-ended question "Could you describe your experiences during the four weeks of Ramadan fasting". As the interview progressed, the other probing questions circled around certain themes, specifically drawing attention to factors affecting performance, such as awareness about fasting consequences, self-control, social support, self-enhancement, and trust.

\subsection{Data Analysis}

The interviews lasted to an approximate time ranging from 30 to 45 minutes in duration. All recorded statements were transcribed verbatim. Measures to ensure a reliable representation of data was taken. First, all participants were provided with the copy of the transcript to check the content and add comments if necessary. Secondly, triangulation followed and the contents of the transcripts were approved. Individual profile of the subjective experiences during the fasting period was developed to further enable the researchers to identify the common and unique discourses (Potter \& Wetherell, 1987) of the interview text. At first, we analyzed the data using Foucauldian Discourse Analysis explained by Carla Willig (2008) (see Roy, 2011) to highlight how cultural requirements rooted within an individual, becomes a disciplinary control within which every individual behave in the society. In addition, our results also highlighted the athlete's adaptive pathway. The meaning units were examined more closely and only those statements viewed as particularly relevant to adaptive mode, were extracted. Each meaning unit was tagged with appropriate adaptive label and the research partners acted as "devils advocate" (Krane, Anderson and Stean, 1997) in questioning the meaning units. The researchers further compared individual statements to reach a consensus on the adaptive dimensions.

\section{Results and Discussion}

The results extracted from the interviews, were treated through Foucauldian discourse analysis to explain socio-cultural influences. The responses profoundly highlight Muslim athlete's individual experiences in relation to fasting during Ramadan month. These results are discussed using Foucauldian's concept of the panopticon (Foucault, 1977) and the adaptive pathway drawn from the raw data shown in Table 1. 
Table 1. Adaptive pathways for regulation

\begin{tabular}{|c|c|c|c|}
\hline Raw data (Extracted statements) & Means and methods & Pathway & Regulation \\
\hline $\begin{array}{l}\text { When I am fasting, I experience difficulty. It is } \\
\text { difficult to perform well. It is difficult in the training } \\
\text { also. Sleep \& thirst feelings during the fasting period. } \\
\text { But I take plenty of fluid... different type of drinks and } \\
\text { different flavors...especially when I begin Ramadan } \\
\text { fast and at the end of fasting. }\end{array}$ & $\begin{array}{l}\text {-Self awareness. } \\
\text {-Role as a Muslim } \\
\text { athlete. } \\
\text {-Contextual challenges. } \\
\text {-Plan in place }\end{array}$ & $\begin{array}{l}\text { Understanding of } \\
\text { the context. }\end{array}$ & \\
\hline $\begin{array}{l}\text { I adjust to the situation... and I am able to control my } \\
\text { feelings. I get excited as I come near the end of } \\
\text { Ramadan fasting period. "I try to remain calm and } \\
\text { have patience during the fasting period." "I try to be } \\
\text { mentally prepared and remain strong." }\end{array}$ & $\begin{array}{l}\text {-Preparation } \\
\text {-Assertiveness } \\
\text {-Management }\end{array}$ & $\begin{array}{l}\text { Control } \\
\text { adjustment. }\end{array}$ & \\
\hline $\begin{array}{l}\text { During Ramadan fasting it feels like ...the time is } \\
\text { moving slowly. I have to wake up early....and then go } \\
\text { for training. I feel tired...but I have the will power to } \\
\text { continue fasting. }\end{array}$ & $\begin{array}{l}\text {-Self-learning } \\
\text {-Effort \& Volition }\end{array}$ & $\begin{array}{l}\text { Will power and } \\
\text { Self-enhancement. }\end{array}$ & Adaptation \\
\hline $\begin{array}{l}\text { Whether we are with the family or in the training } \\
\text { camp or in the context of competition, we begin the } \\
\text { fasting day with morning prayers recited together. The } \\
\text { same happens when we break the fast in the evening. } \\
\text { In the teachings of Islam, Muslims engage in fasting } \\
\text { during Ramadan. We all do. }\end{array}$ & $\begin{array}{l}\text {-Group } \\
\text {-Team } \\
\text {-Family }\end{array}$ & $\begin{array}{l}\text { Belonging } \\
\text { gravitating. }\end{array}$ & \\
\hline $\begin{array}{l}\text { We trust our friends and they encourage us constantly, } \\
\text { "We look forward." "We are trained to handle the } \\
\text { situations. There is no undue pressure...our coach } \\
\text { understands the situation." We have to train as the } \\
\text { tournament is round the corner. }\end{array}$ & $\begin{array}{l}\text {-Coach } \\
\text {-Support staff } \\
\text {-Team members }\end{array}$ & Trust and support. & \\
\hline
\end{tabular}

\subsection{Compliance to Socio-cultural Practice: Fasting vs Athleticism}

Fasting is a mandatory practice in Islamic religion which requires every Muslim to fast from dawn to dusk for a period of 30 days. It is natural that any individual would face some difficulties during fasting period to adapt and cope with this practice. Thus, the participants of this study are no exception to this. The most common difficulties experienced were low concentration, exhaustion, tiredness, fatigue, lack of energy, hunger, thirst, dehydration, dizziness and overall uneasiness which are verified in the following examples.

Examples:

Athlete A: "On the first day of Ramadan, I wake up very early in the morning and eat as much as possible but by the time the training begins, I feel sleepy because my stomach is full and besides, I woke up very early that day."

This statement points to how sleep interferes with the training. In Malaysia, during the fasting month, athletes change their usual sleeping timing to adhere to the socio-cultural and religious practices within their country.

Athlete B "By the time the training begins, the food I ate would have already got digested and I can feel the hunger pangs in my stomach..... I would feel quite thirsty by the end of the training because of the heat conditions in this country sometimes."

A description of dehydration is manifested in the statement by athlete B. The statement also points out on how the hot environment affects the physiological state and training of the athletes. Athletes adhering to the Socio-cultural practice of fasting would not have an opportunity to hydrate themselves until the iftar meal (breaking of the fast).

Athlete C: "Even though we eat plentiful in the morning, by the time it is afternoon, our second training session begins and I would feel very tired and uncomfortable by then.... I feel that there is no energy to train because I have not eaten anything since morning." 
Athlete D: "....Malaysia is a hot country and we train under the hot sun for a long time. I feel dehydrated and exhausted to train under these conditions especially when I am fasting."

The statements from athlete $\mathrm{C}$ and athlete $\mathrm{D}$ highlights how the training volume and intensities affect the physiological responses in an athlete's body, leading to psychological experiences of lack of energy, fatigue and overall uneasiness. As reported by Leiper, Molla and Molla (2003) relative to food, the restriction on fluid intake during the fasting period directly impacts the regulation of body core temperature.

Fasting is an unavoidable practice for every individual who follows Islam as their religion. Having understood the importance of fasting from childhood, most Muslim athletes do not compromise on this practice except under certain circumstances like competing at major tournaments. Analyzing the data using Foucault's lens (Roy, 2011) the above context clearly indicates how the power workings (Foucault, 1977) of Islamic culture, influence the individual's knowledge and understanding towards fasting during Ramadan. Although, there are no previous studies to support this result, we could however substantiate it with Brown's (2000) statement that every individual gravitate through their practices.

Drawing the results from a holistic point of view, we found that each athlete held a subjective position of a true Islamic follower who would follow the fasting practices irrespective of experiencing difficulty associated with fasting and physical exertion (training). We made a unanimous conclusion to the subjective position because the athletes themselves have revealed that they do compromise on fasting during major tournaments, however; they would fulfill the 30 days of fast even after Eid-ul-Fitr or Eid (festivity that marks the end of Ramadan).

Example:

Athlete A: "I did fast once and performed during the competition but failed to win. I could not concentrate because I was feeling hungry and tired. So I don't fast during tournament period. I would finish with the competition and later continue fasting to fulfill the 30 days of fast after Ramadan."

From the interview transcripts we understood that archers commonly experienced certain feeling such as exhaustion, tiredness, fatigue, lack of energy, hunger, thirst, dehydration, low concentration, dizziness and overall uneasiness. Although, athletes have experienced difficulties to train while fasting, yet they follow fasting practice because of their faith, their respect and compliance to their religious and socio-cultural requirements. Thus, this devotion shown toward the socio-cultural practices and religious obligations, preserving the values of Islam, accredits them as true disciple of their faith.

\subsection{Socio-cultural Practices and Sports Performance: Adaptation Pathway}

In the earlier works by Taylor (1983), adaptation included meaning, mastery and self-enhancement as the core motives. Extending on this work, Fiske (2004) re-conceptualized adaptation into five entry pathways (viz) understanding, control, self-enhancement, trust, and belonging. The framework of adaptation pathway by Fiske (2004) draws similarities to some extent while explaining the adaptation in the Ramadan fasting. The statement extracts shown in Table 1 highlights the means and methods leading to a pathway explaining the adaptation among the athletes.

\subsubsection{The Pathway of Understanding and Contextual Adaptation}

The Muslim athletes clearly understands their personal cultural practices (Ramadan fasting) and performance context (competition during Ramadan fasting). Insights into contextual challenges include the awareness that individuals who are non Muslims are not required to adhere to fasting. Thus, a reciprocal socio-cultural understanding from non Muslim elite athletes who are a part of the sport team is evident.

To avoid monotony, variations included even in dietary patterns can be considered as an adaptive strategy. Our observations in the applied sports settings also provided anecdotal evidence that athletes usually consumed their favorite food and chose to take liquid in different flavors, probably ensuring additional intake.

Example:

The following statement from the athlete shows that the athlete understands the need to avoid dehydration during sports training.

\section{"I drink plenty of fluid"}

Malaysia is a multicultural country; however, during Ramadan fasting, most of the restaurants and food outlets remain closed. These actions can be attributed to contextual understanding and adaptation. In other words, it is not just the athletes, but the society also understands and respects the context and adopts adaptive measures. 
Better understanding of difficulties (e.g., headaches and feelings of fatigue) as a part and parcel of fasting, helps in increased acceptance and reconciliation.

\subsubsection{The Pathway of Control and Adjustments}

Pathway of control reflects appropriate assertiveness and preparation derived from accurate understanding. Mental aspects (e.g., high level of concentration) and recovery are vital during important competitions. More specifically, athletes were told to minimize the social activities as far as possible. Modern day advancement impels the athletes to spent time on the internet which often interferes with the sleep time, affecting the recovery. This would particularly hinder the chances of success in competition. Schinke et al. (2007) mentions that every professional athlete needs to establish some control over self and context. Control represents self-confidence, avoiding distraction and being assertive. To impede the tendency of getting obsessively passionate of social activities (e.g., web browsing, facebook, online chat) efforts to educate and inculcate a new habit is imperative. This could be classified as control over self and the context. In relation to control, another example would be a context such as London Olympics, 2012, where most non Muslim athletes would be consuming food during the day time and some Muslim athletes would be engaging in fasting. Thus, contingency plans such as "distraction control" were drawn out. Trying to remain calm and being mentally prepared could reflect controlling strategies. These are somewhat evident in the following statements.

\section{Example}

"I am able to control my feelings" (management).

"I adjust to the situation" (assertiveness).

"I try to be mentally prepared" (preparation).

\subsubsection{Pathway of Will Power and Self-enhancement}

Pathway of willpower and self-enhancement propels athletes to strive to make additional effort to gather new information and methods to tide over the challenges of competing while fasting. One way that facilitates an easy path is using experiences of previous year's training/competition during fasting.

In Archery, the athletes need to stay focused during the long training hours requiring them to remain committed and put in additional effort. For example, the following statements from the athletes reflect that spirituality associated with the Ramadan fasting provided some kind of mental strength and will power to maintain calm and composure throughout the fasting period.

Example:

"I have to go for training" (learning).

"I have to wake up early" (effort).

"I have the will power" (Volition).

It is likely that the spiritual dimension acted as a unifying force for self-enhancement. In other words, the spirituality associated with Ramadan created a strong bond between the individual beliefs, personal fulfillment and commitment to socio-cultural practices.

\subsubsection{Pathway of Belonging and Gravitating}

Pathway of belonging gestures support to establish healthy and stable relationships. The pathway of "belonging" includes gestures of support, which is basically derived from other Muslim athletes practicing Ramadan fasting.

For example, gathering among fasting athletes for prayers or informal meetings prior to breaking the fast provides social support, which can be classified as adaptive measure. Thus, social support was an integral part of the team process even if the athletes belong to individual sports. The following statements reflect the importance of belonging.

Example:

\section{"We begin with prayers together" (group), whether we are with the family or in the camp (family/team).}

One unique aspect is that athletes and coaches bond together to facilitate better adaptation in sports training for Muslim archers during Ramadan fasting. The participants in this study are drawn from a collectivist culture where individuals are functionally interdependent. Unlike cultures with individualistic values, conformity to social norms is typically observed. A case in point in the sports setting is the training time modifications to suit the fasting context. Interestingly, all team members abide by the changes irrespective of different socio-cultural background. This action cuts through cultural and religious barriers highlighting the spirit of belonging. 


\subsubsection{The Pathway of Trust and Support}

The pathway of trust and support signifies the degree of confidence among individuals. "Trust" elicits appropriate guidance to overcome the dilemma of one's socio-cultural practices in an unfamiliar context (e.g., Competition venue). The trust and support from one's peer is as vital as the trust that an athlete gets from "a significant other" (e.g., coach/manager); this also lays a strong foundation for enhancing feeling of oneness (e.g., to a particular faith/group/or practices). Trust and support is important in contemporary times, where, elite sports teams often consist of individuals from different background. The smooth interactions in a team uphold the importance of trust. Trust was further enhanced when the coaches, and non Muslim athletes, were willing to cooperate and not thrust unwanted pressure considering the fasting context, which is evident in the following statements.

Example:

"Our coach understands and we trust our friends in the team".

"We are trained to handle the situation".

\section{Concluding Remarks}

Socio-cultural practices within one's context assigns a prominent influence on an athlete's life within sports regime. The study further highlights the adaptive pathways where the athletes attempt not only to make coping efforts, but also coordinate regulation strategies for typical sport related issue. Additionally, the responses from the athletes represent their attempt to transfer the learning within one's culture, to different competitive contexts. Given the importance of maintaining personal beliefs, values, and spirituality from one context, and upholding it in another context, adaptation calls for additional framework of directions.

\section{Limitations}

The current study has a number of potential limitations and caution is advised while interpreting the findings. First, the study considered only a small sample from a particular sport; thus a larger pool of athletes from different sports would provide more insights. It is possible that individual experiences can be different as the intensity of training and demands of different levels of competitions are not the same. Second, our interpretations are based on data drawn from Malaysian Muslim archers within the specific socio-cultural practices in the country. The extents of similar influences among Muslims engaged in Ramadan fasting from other countries are not addressed. Third, our study is based on qualitative interview and it is possible that all the aspects of the subjective experiences were not fully captured. Future studies can empirically examine the impact of socio-cultural practice of Ramadan fasting on high level competitions. Fourth, although Ramadan fasting has a religious connotation, we considered it as a socio-cultural practice because fasting practices and contextual adaptations vary in different countries.

\section{Acknowledgement}

We thank Nazirah Gulam Mohamed from USM for supporting the Ramadan research. We also extend our thanks to Abdul Rashid Aziz from Singapore Sports Institute for providing valuable suggestions.

\section{References}

Aziz, A. R., \& Weileen, P. (2008). Practical tips to exercise training during the Ramadan fasting month. ISN bulletin, 1(1), 13-19.

Brown, D. (2000). Angels and Demons (pp. 133). Great Britain: Corgi Books.

Cole, C. L., Giardian, M. D., \& Andrews, D. L. (2004). Michel Foucault: Studies of power and sport. In R. Giulianotti (Ed.), Sport and Modern Social Theorists (pp. 207-211). Palagrave Macmillan.

Easterberg, K.G. (2002). Qualitative Methods in Social Research. Toronto: McGraw-Hill.

Fiske, S. T. (2004). Social beings: A core motives approach to social psychology. Danvers, MA: Wiley \& Sons.

Foucault, M. (1977). Discipline and Punish: The Birth Of The Prison. Penguin, London.

Hanin, Y. L. (2000). Emotions in Sports. Human Kinetics, Champaign, IL.

Kadri, N., Tilane, A., El Batal, M., Taltit,Y., Tahiri, S. M. \& Moussaoui, D. (2000). Psychosomatic Medicine, 62, 280-285.

Krane, V., Anderson, M., \& Steam. (1997). Issues of Qualitative research methods and presentation. Journal of Sports and Exercise Psychology, 19, 280-285. 
Leiper, J. B., Molla, A. M., \& Molla, A. M. (2003). Effects on health of fluid restriction during fasting in Ramadan. European Journal of Clinical Nutrition, 57(suppl.2), S30-S38. http://dx.doi.org/10.1038/sj.ejen.1601899

Liem, G. A. D., Martin, A. J., Porter, A .L., \& Colmar. S. (2012). Socio-cultural antecedents of academic motivation and achievement: Role of values and achievement motives in achievement goals and academic $\begin{array}{lllll}\text { performance. Asian Journal of Social Psychology, } & 15, & 1-13 .\end{array}$ http://dx.doi.org/10.1111/j.1467-839X.2011.01351.x

Markulla, P., \& Pringle R. (2006). Foucault, Sport and Exercise: Power, Knowledge and Transforming the Self. London: Routledge.

Mio, J. S., Barker-Hackett, L., \& Tumambing, J. (2006). Multicultural Psychology: Understanding our diverse communities. Boston: McGraw-Hill.

Potter, J., \&Wetherell, M. (1987). Discourse and Social Psychology: Beyond Attitudes and Behaviour. Los Angeles: Sage.

Roy, A. (2011). Beyond disability and ethnicity challenges: Narrative of a Paralympian. International Journal of Sociology and Anthropology, 3(11), 430-435.

Roy, J., Hamidan, S., \& Singh, R. (2011a).Temporal patterns of subjective experiences and self-regulation during Ramadan fasting among Elite Archers: A qualitative Analysis. Asian Journal of Sports Medicine, 2, 195-204.

Roy, J., Hwa, O. C., Singh R., Aziz, A. R., \& Jin, C. W. (2011b). Self generated coping strategies among Muslim athletes during Ramadan fasting. Journal of Sports Science and Medicine, 10, 137-144.

Schinke, R. J., Gauthier, A. P., Dubuc, N. G., \& Crowder, T. (2007). Understanding athlete adaptation in the National Hockey League through an archival data source. The Sport Psychologist, 21, 277-287.

Schinke, R. J., Michel, G., Gauthier, A. P., Danielson, R., Pickard, P., Peltier, D., \& Peltier, M. (2006). Adaptation to the mainstream in elite sport: An aboriginal Perspective. The Sport Psychologist, 24, 542-543.

Schinke, R. J., Tenenbaum, G., Lidor, R., \& Battochio, R. C. (2010). Adaptation in action: The transition from research to intervention. The Sport Psychologist, 24, 542-543.

Singh, R., Hwa, O. C., Roy, J., Jin, C. W., Ismail, S. M., Lan, M. F., Hiong, L. L., \& Aziz, A. R. (2011). Asian Journal of Sports Medicine, 2, 167-176.

Taylor, S. E. (1983). Adjustment to threatening events: A theory of cognitive adaptation. The American Psychologist, 38, 1161-1173. http://dx.doi.org/10.1037/0003-066X.38.11.1161

Tenenbaum, G., Jones, C. M., Kitsantis, A., Sachs, D. N., \& Berwick, J. P. (2003). Failure adaptation: An investigation of the stress response process in sport. International Journal of Sport Psychology, 34, 27-62.

Tian, H. H., Aziz, A. R., Png, W., Wahid, M .F., Yeo, D., \& Png, A. C. (2012). Effects of fasting during Ramadan month on cognitive function in Muslim athletes. Asian Journal of Sports Medicine, 2, 145-153.

Willig, C. (2008). Discourse Analysis. In Smith, J. A. (Ed), Qualitative Psychology: A practical Guide to Research Methods. Los Angeles: Sage. 